\title{
PENGARUH KECERDASAN EMOSIONAL, MOTIVASI DAN KOMITMEN TERHADAP KINERJA GURU DI SMA PERSIAPAN STABAT KABUPATEN LANGKAT
}

\author{
Khairil Efendi \\ Universitas Islam Sumatera Utara \\ khairil.efemdi@gmail.com
}

\begin{abstract}
The formulation of the problem in this study is How is the influence of Emotional Intelligence, Motivation and Commitment to Teacher Performance in SMA Persiapan for Stabat Langkat Regency, both partially and simultaneously. The population and sample of this study were all teachers at the foundation, amounting to 37 people. The sampling technique uses total sampling. Data collection techniques used were direct interviews and questionnaires. The results of this study are partially the Emotional Intelligence variable has a positive and significant effect on Teacher Performance with tcount> ttable, $(2,432>2.04$,$) , Motivation variable has a positive and significant effect on Teacher$ Performance with tcount $>$ ttable, $(3,712>2,04)$ and Commitment Variables have a positive and significant effect on Teacher Performance with tcount> ttable, (3.830> 2.04). Simultaneously the variables of Emotional Intelligence, Motivation and Commitment have a positive and significant effect on Teacher Performance with Fcount> Ftable, (12,201> 2.87). R2 (RSquare) value of 0.540, which means that the variable Emotional Intelligence, Motivation and Commitment has a positive and significant effect on Teacher Performance in SMA Persiapan for Stabat Langkat Regency by 55.60\%, and the remaining $44.40 \%$ again, influenced by factors other factors not examined.
\end{abstract}

Keywords: Emotional Intelligence, Motivation, Commitment and Teacher Performance

ABSTRAK : Rumusan masalah dalam penelitian ini adalah Bagaimana pengaruh Kecerdasan Emosional, Motivasi dan Komitmen Terhadap Kinerja Guru di SMA Persiapan Stabat Kabupaten Langkat baik secara parsial maupun simultan. Populasi dan sampel penelitian ini adalah seluruh guru di yayasan tersebut yang berjumlah 37 orang. Teknik pengambilan sampel menggunakan total sampling. Teknik pengumpulan data yang digunakan adalah wawancara langsung dan angket. Hasil penelitian ini adalah secara parsial variabel Kecerdasan Emosional berpengaruh Positif dan signifikan terhadap Kinerja Guru dengan nilai $t_{\text {hitung }}>t_{\text {tabel, }}(2,432>2,04$, $)$, variabel Motivasi berpengaruh Positif dan signifikan terhadap Kinerja Guru dengan nilai $t_{\text {hitung }}>t_{\text {tabel, }}(3,712>2,04)$ dan Variabel Komitmen berpengaruh positif dan signifikan terhadap Kinerja Guru dengan nilai thitung $>t_{\text {tabel, }}(3,830>2,04)$. Secara Simultan variabel Kecerdasan Emosional, Motivasi dan Komitmen berpengaruh positif dan signifikan terhadap Kinerja Guru dengan nilai $F_{\text {hitung }}>F_{\text {tabel, }}(12,201>2,87$ ). Nilai $R^{2}$ (RSquare) sebesar 0.540, yang berarti bahwa variabel Kecerdasan Emosional, Motivasi dan Komitmen berpengaruh Positif dan signifikan terhadap Kinerja Guru di SMA Persiapan Stabat Kabupaten Langkat sebesar 55,60\%, dan sisanya sebesar 44,40\% lagi, dipengaruhi oleh faktor-faktor lain yang tidak diteliti.

Kata Kunci : Kecerdasan Emosional, Motivasi, Komitmen dan Kinerja Guru

\section{Pendahuluan}

Guru adalah pendidik profesional dengan tugas utama mendidik, mengajar, membimbing, mengarahkan, melatih, menilai dan mengevaluasi peserta didik pada pendidikan anak usia dini jalur pendidikan formal, pendidikan dasar, dan pendidikan menengah. Sebagai profesi, guru memiliki standar kualitas yang diatur oleh UU RI No. 14/2005 tentang Guru dan Dosen, Bab IV pasal 8 yang menyatakan bahwa "guru wajib memiliki kualifikasi akademik, kompetensi, sertifikat pendidik, sehat jasmani dan rohani, serta memiliki kemampuan untuk mewujudkan tujuan pendidikan nasional". Kompetensi yang dimaksud dalam undang-undang ini adalah kompetensi pedagogik, kompetensi kepribadian, kompetensi sosial, dan kompetensi profesional. Untuk mendapatkan empat kompetensi tersebut 
maka calon guru harus melalui pendidikan profesi di Lembaga Pendidikan Tenaga Kependidikan (LPTK). Nurdin (2009:65) menyatakan bahwa kompetensi yang paling mudah diteliti dan diukur salah satunya yaitu kompetensi profesional guru. Menyoroti kompetensi profesional guru memang membutuhkan penjabaran dan deskripsi yang jelas agar memperoleh gambaran menyeluruh mengenai konsep kompetensi professional tersebut. Namun, kompetensi profesional perlu diwujudkan pula dalam bentuk standar kompetensi yang memadai dan hal tersebut memerlukan alat ukur dan alat kontrol yang tepat agar semua guru dapat dan mampu mencapai kompetensi profesional yang diharapkan.

Kinerja guru memang dipengaruhi oleh faktor psikologis yaitu kecerdasan emosional. Dimana kecerdasan emosional dapat membawa keberhasilan pada sebuah kinerja seorang guru pada khususnya, karena kecerdasan emosional yang baik melahirkan pemikiran, perasaan, perilaku, dan tujuan pengelola dengan sikap (1) disiplin diri, jujur dan tulus kepada diri sendiri, membangun kekuatan pribadi, termasuk kesadaran diri, mendengarkan suara hati, hormat, tanggungjawab dan koneksi, (2) memantapkan diri dan maju terus, membangun inspirasi diri sendiri dan orang lain, termasuk keaslian, keuletan, dan hubungan saling percaya, (3) membangun watak dan kewibawaan, mengembangkan potensi, integritas, dan tujuan hidup, dan (4) merasakan peluang dan menciptakan masa depan, membangun titik temu, inovasi, intuitif, transformasi, situasional, dan kecerdasan yang luwes.

Baik tidaknya kinerja guru dapat dilihat dari kompetensi yang meliputi penguasaan terhadap bahan pengajaran, pengelolaan program belajar mengajar, pengelolaan kelas, penggunaan media, penguasaan landasan pendidikan, pengelolaan interaksi belajar mengajar, penilaian prestasi siswa dan pengenalan fungsi bimbingan dan penyuluhan di sekolah.

Disamping itu keberhasilan siswa dalam proses pembelajaran dapat juga dipengaruhi oleh faktor dari dalam individu. Faktor dari dalam individu meliputi fisik dan psikis, contoh faktor psikis diantaranya adalah motivasi.

Motivasi guru yang tinggi dapat menunjang keberhasilan belajar, akan tetapi motivasi yang rendah merupakan hambatan yang dapat berakibat pada hasil belajar yang rendah. Untuk itu guru harus dapat memilih model atau metode yang tepat agar tercipta situasi pembelajaran yang menarik dan menumbuhkan motivasi guru sehingga guru merasakan kepuasan dalam melaksanakan proses belajar mengajar.

Faktor lain yang merupakan indikator baik tidaknya kinerja guru adalah komitmen dalam menyelesaian tugas dan pencapaian hasil belajar siswa. Karena dengan komitmen yang tinggi maka pelaksanaan tugas menjadi lebih mudah dan lancar, jika ada kesulitan bisa mencari solusi pemecahannya. Ditambah lagi dengan adanya perhatian, bimbingan dan penghargaan dari kepala sekolah akan menambah semangat kerja dari guru-guru. Adanya jaminan kesejahteraan dan ketersediaan sarana dan prasarana yang mendukung pelaksanaan tugasnya guru merasa tenang dan nyaman serta lebih mudah menyelesaikan tugasnya. Hal ini tentu akan mempengaruhi kinerjanya. Jadi dapat disimpulkan bahwa kinerja guru adalah kemampuan guru yang di wujudkan melalui kemampuan guru tersebut mengelola kecerdasan emosionalnya, motivasi yang tinggi serta mempunyai komitmen yang tinggi pula untuk melaksanakan tugasnya sebagai seorang guru yang kompeten dalam menerapkan ide, gagasan dan konsep yang menimbulkan tercapainya tujuan kegiatan belajar mengajar secara tuntas.

\subsection{Rumusan Masalah}

Perumusan masalah dalam penelitian ini melihat bagaimana Pengaruh Kecerdasan Emosional, Motivasi dan Komitmen terhadap Kinerja guru di SMA Persiapan Stabat Kabupaten Langkat.

\subsection{Batasan Masalah}

Dari hasil identifikasi masalah tersebut, maka penulis membatasi penelitian ini hanya pada Kecerdasan Emosional, Motivasi, Komitmen dan Kinerja guru di SMA Persiapan Stabat Kabupaten Langkat".

\subsection{Hipotesis}

Hipotesis dalam penelitian ini adalah melihat pengaruh Kecerdasan Emosional, Motivasi dan Komitmen berpengaruh terhadap Kinerja guru di SMA Persiapan Stabat Kabupaten Langkat.

\subsection{Tujuan Penelitian}

Penelitian ini bertujuan untuk mengetahui

a. Pengaruh Kecerdasan Emosional terhadap Kinerja guru di SMA Persiapan Stabat Kabupaten Langkat.

b. Pengaruh Motivasi terhadap Kinerja guru di SMA Persiapan Stabat Kabupaten Langkat. 
c. Pengaruh Komitmen terhadap Kinerja guru di SMA Persiapan Stabat Kabupaten Langkat.

d. Pengaruh Kecerdasan Emosional, Motivasi dan Komitmen terhadap Kinerja guru di SMA Persiapan Stabat Kabupaten Langkat.

\section{Metode Penelitian}

\subsection{Populasi dan Sampel}

Populasi dalam penelitian ini adalah seluruh guru-guru PNS di SMAN 6 Binjai Kecamatan Binjai Utara yang berjumlah 64 orang.

Menurut Arikunto (2006:134), sampel adalah bagian dari populasi yang mempunyai peluang/estimasi yang sama untuk menjadi sampel. Apabila subjeknya kurang dari 100, lebih baik diambil seluruhnya sehingga penelitiannya merupakan penelitian populasi. Tetapi jika jumlah subjeknya lebih besar dari 100, maka dapat diambil sampel antara $10-15 \%$ atau 20$24 \%$ atau lebih. Dengan demikian merujuk dari pernyataan diatas maka sampel dalam penelitian ini seluruh populasi yang berjumlah 64 orang guru.

\subsection{Uji Normalitas Data}

Uji normalitas Kolmogorov Smirnov adalah dengan membandingkan distribusi data (yang akan diuji normalitasnya) dengan distribusi normal baku. Distribusi normal baku adalah data yang telah ditransformasikan ke dalam bentuk ZScore dan diasumsikan normal. Jadi sebenarnya uji Kolmogorov Smirnov adalah uji beda antara data yang diuji normalitasnya dengan data normal baku.

Seperti pada uji beda biasa, jika signifikansi di bawah 0,05 berarti terdapat perbedaan yang signifikan, dan jika signifikansi di atas 0,05 maka tidak terjadi perbedaan yang signifikan. Penerapan pada uji Kolmogorov Smirnov adalah bahwa jika signifikansi di bawah 0,05 berarti data yang akan diuji mempunyai perbedaan yang signifikan dengan data normal baku, berarti data tersebut tidak normal.

Tabel 1. Uji Kolmogorov Smirnov

One-Sample Kolmogorov-Smirnov Test

\begin{tabular}{|ll|r|r|r|r|}
\hline & & X1 & \multicolumn{1}{c|}{ X2 } & X3 & \multicolumn{1}{c|}{$\mathrm{Y}$} \\
\hline $\mathrm{N}$ & Mean & 37 & 37 & 37 & 37 \\
& 36.127 & 36.1432 & 36.2451 & 36.3124 \\
Normal Parameters $^{\mathrm{a}, \mathrm{b}}$ & Std. & 0.6523 & & & \\
& Deviation & 4 & 0.63190 & 0.52371 & 0.15648 \\
& Absolute & .162 & .170 & .168 & 0.582 \\
Most Extreme & Positive & .182 & .186 & .079 & .069 \\
Differences & Negative & -.012 & -.067 & -.045 & .025 \\
& 1.452 & 1.369 & 1.512 & .741 \\
Kolmogorov-Smirnov Z Z & .179 & .198 & .179 & .091 \\
Asymp. Sig. (2-tailed) & & & & \\
\hline
\end{tabular}

Dari tabel 1, diatas dapat dilakukan uji :

Kolmogorov - Smirnov Z $<1,97$

$$
\begin{aligned}
& \mathrm{X} 1=1,452<1,97 \\
& \mathrm{X} 2=1,369<1,97 \\
& \mathrm{X} 3=1,512<1,97 \\
& \mathrm{Y}=0,91<1,97
\end{aligned}
$$

Asymp Sig (2Tailed) > Level Sig. 5\% (0,05)

$\mathrm{X} 1=0,179>0,05$

$\mathrm{X} 2=0,198>0,05$

$\mathrm{X} 3=0,179>0.05$

$\mathrm{Y}=0,091>0,05$

Melihat hasil pengolahan data dengan bantuan program SPSS diatas maka dapat disimpulkan bahwa seluruh data dalam penelitian ini berdistribusi dengan normal.

\subsection{Uji Multikolinearitas}

Uji ini dilakukan untuk melihat dan meyakinkan bahwa variabel - variabel bebas dalam penelitian ini terbebas dari saling mempengaruhi. Uji ini dinyatakan terkena Multikolinieritas atau tidak dilihat dari nilai Tolerance yang ada pada kolom Collinearity Statistic menunjukkan nilainya lebih kecil dari 1 , atau dapat juga dilihat dari nilai VIF yang bernilai harus lebih kecil dari 5 (Suliyanto, 2011:82). Untuk mengetahui uji ini dapat dilihat

\begin{tabular}{|c|c|c|}
\hline \multirow[t]{2}{*}{ Model } & \multicolumn{2}{|c|}{ Collinearity Statistics } \\
\hline & Tolerance & VIF \\
\hline $\mathrm{X} 1$ & .712 & 6.355 \\
\hline $1 \mathrm{X} 2$ & .618 & 5.625 \\
\hline $\mathrm{X} 3$ & .633 & 5.782 \\
\hline
\end{tabular}
pada tabel berikut ini:

Tabel 2. Uji Multikolinieritas Coefficients $^{\text {a }}$ 
Jika dilihat pada tabel 2, diketahui bahwa variabel kecerdasan emosional $\left(\mathrm{X}_{1}\right)$, Motivai $\left(\mathrm{X}_{2}\right)$ dan komitmen $\left(\mathrm{X}_{3}\right)$ telah terbebas dari Multikolinieritas dimana masing - masing nilai VIF lebih kecil dari 10.

\subsection{Uji Heteroskedastisitas}

Uji heteroskedastisitas bertujuan untuk melihat apakah di dalam model regresi terjadi ketidaksamaan variabel dari residual satu pengamatan ke pengamatan yang lain. Pada uji ini digunakan metode Scatter plot yang dapat dilihat pada gambar berikut ini:

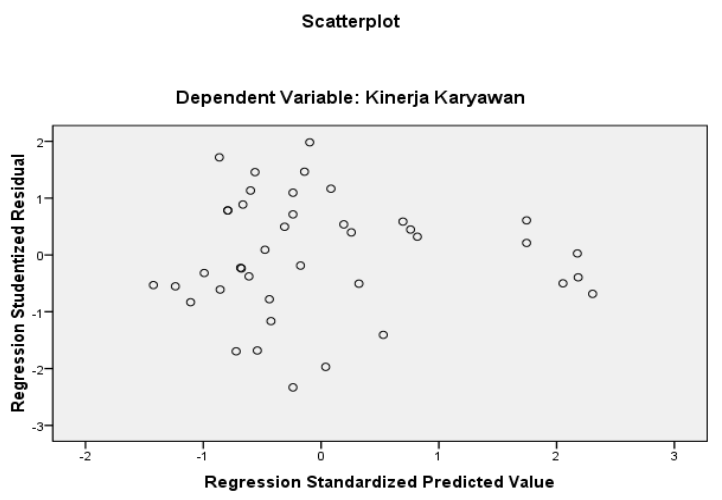

Gambarl Grafik scatterplot Uji Heteroskedastisitas
Uji ini akan dinyatakan terbebas dari heteroskedastisitas jika titik - titik yang terdapat pada gambar tersebar secara merata. Meratanya titik - titik ini diketahui bahwa titik - titik tersebar diantara titik 0. Melihat pada gambar 4.1 diketahui bahwa titik - titik tersebar merata mengikuti diantara titik 0 . Ini dapat dikatakan bahwa data telah terbebas dari masalah heteroskedastisitas.

\section{Hasil dan Pembahasan \\ 3.1. Analisis Regresi Linier Berganda}

Berdasarkan olahan data yang telah dilakukan, maka dapat diketahui bahwa model hubungan dari analisis regresi linear berganda ini dilihat dari tabel berikut ini:

Tabel 3. Regresi Linear Berganda

Coefficients $^{\mathrm{a}}$

\begin{tabular}{|c|c|c|c|c|c|}
\hline \multirow[t]{2}{*}{ Model } & \multicolumn{2}{|c|}{$\begin{array}{c}\text { Unstandardized } \\
\text { Coefficients }\end{array}$} & $\begin{array}{c}\text { Standardized } \\
\text { Coefficients }\end{array}$ & \multirow[t]{2}{*}{$\mathrm{t}$} & \multirow[t]{2}{*}{ Sig. } \\
\hline & B & Std. Error & Beta & & \\
\hline \multirow{4}{*}{$\begin{array}{ll} & \text { (Constant) } \\
1 & \begin{array}{l}\text { Kec.Emosional } \\
\text { Motivasi } \\
\text { Komitmen }\end{array}\end{array}$} & 5.689 & 0.652 & & 6.712 & .000 \\
\hline & .593 & .164 & .260 & 2.432 & .001 \\
\hline & .564 & .278 & .472 & 3.712 & .000 \\
\hline & .549 & .290 & .311 & 3.830 & .001 \\
\hline
\end{tabular}

a. Dependent Variable: Kinerja Guru

Berdasarkan pada tabel V.13 maka dapat disusun model penelitian ini adalah sebagai berikut:

$$
Y=5,733+0,662 X_{1}+0,192 X_{2}
$$

Dilihat dari persamaan linear tersebut, maka dapat dikatakan bahwa hubungan dalam model penelitian ini adalah hubungan linear positif. Model penelitian dalam bentuk persamaan regresi linear berganda diatas dapat diartikan sebagai berikut:

a. Diketahui ketika Gaya Kepemimpinan $\left(X_{1}\right)$ dan Motivasi $\left(\mathrm{X}_{2}\right)$ tidak mengalami perubahan, maka nilai dari Kinerja karyawan adalah sebesar 5,733 satuan.

b. Ketika Gaya Kepemimpinan $\left(\mathrm{X}_{1}\right)$ mengalami perubahan pada satuan tertentu maka akan dapat meningkatkan kinerja karyawan sebesar 0,662 satuan dengan asumsi bahwa variabel lainnya tidak mengalami perubahan.

c. Ketika Motivasi $\left(\mathrm{X}_{2}\right)$ mengalami perubahan pada satuan tertentu maka akan dapat meningkatkan kinerja karyawan sebesar 0,192 satua dengan asumsi bahwa variabel lainnya tidak mengalami perubahan.

\subsection{Hipotesis}

\subsubsection{Pengujian Hipotesis Secara Simultan}

Uji serempak dilakukan untuk melihat tingkat signifikansi Gaya Kepemimpinan dan Motivasi secara Simultan terhadap Kinerja. Hasil uji secara simultan dapat dilihat pada tabel di bawah ini: 
Tabel 4. Hasil Uji Serempak

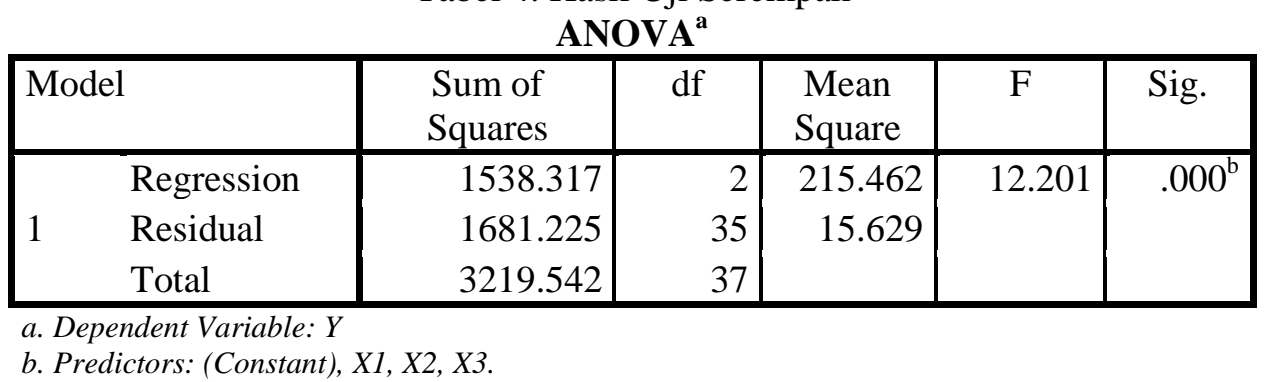

Pengujian hipotesis dilakukan dengan cara membandingkan besarnya angka $\mathrm{F}$ penelitian dengan $\mathrm{F}$ tabel, dengan kriteria sebagai berikut:

Jika $\mathrm{F}_{\text {hitung }}>\mathrm{F}_{\text {tabel }}$, maka $\mathrm{H}_{0}$ ditolak dan $\mathrm{Ha}$ diterima

Jika $\mathrm{F}_{\text {hitung }}<\mathrm{F}_{\text {tabel}}$, maka $\mathrm{H}_{0}$ diterima dan $\mathrm{Ha}$ ditolak

Berdasarkan tabel 5.16, angka $\mathrm{F}$ penelitian yang diperoleh dari hasil perhitungan adalah sebesar 12.201 Sedangkan angka $F$ tabel dihitung dengan taraf signifikansi 95\% dan alpha 5\% serta derajat kebebasan (dk) dengan ketentuan $\mathrm{dk}=\mathrm{n}-2$ atau 37-2 $=35$, maka diperoleh angka Ftabel $=$ 2,87 .

Dengan demikian nilai $\mathrm{F}_{\text {hitung }}=12.201>\mathrm{F}_{\text {tabel }}$ $=2,87$, dengan nilai signifikansi $0,00<0,05$. karena $\mathrm{F}_{\text {hitung }}>\mathrm{F}_{\text {tabel }}$ yang berarti bahwa $\mathrm{H}_{0}$ ditolak dan Ha diterima, sehingga dapat disimpulkan bahwa Kecerdasan Emosional, Motivasi dan Komitmen berpengaruh positif dan signifikan terhadap Kinerja Guru di SMA Persiapan Stabat Kabupaten Langkat.

\subsubsection{Pengujian Hipotesis Secara Parsial}

Pengujian secara parsial merupakan pengujian atas variabel bebas terhadap terikat secara satu persatu. Pada pengujian ini akan dibandingkan nilai $t_{\text {hitung }}$ dengan nilai $t_{\text {tabel }}$. Untuk mengetahui nilai $t_{\text {tabel }}$ terlebih dahulu ditentukan besarnya nilai derajat bebas (degree of freedom) dari data penelitian.

Berdasarkan pada tingkat kepercayaan penelitian sebesar 95\% dan tingkat Alpha sebesar 5\% dengan penelitian metode dua sisi, maka dapat ditentukan nilai derajat bebas pada penelitian ini dengan menggunakan rumus $\mathrm{n}-\mathrm{k}$ - 1 , dimana $\mathrm{n}$ adalah jumlah responden dan $\mathrm{k}$ adalah jumlah variabel bebas pada penelitian ini. Berdasarkan jumlah data pada penelitian ini sebanyak 91 responden, maka dapat ditentukan nilai derajat bebas penelitian ini adalah $91-2-1$ $=88$. Dengan jumlah derajat bebas sebesar 88 maka dapat ditentukan besarnya nilai $t_{\text {tabel }}$ adalah sebesar 1,987.

Data pengujian secara parsial ini dapat dilihatkan seperti pada tabel berikut ini:

Tabel 5. Hasil Uji Parsial

Coefficients $^{\mathrm{a}}$

\begin{tabular}{|l|r|r|r|r|r|}
\hline \multirow{2}{*}{ Model } & \multicolumn{2}{|c|}{$\begin{array}{c}\text { Unstandardized } \\
\text { Coefficients }\end{array}$} & \multicolumn{1}{c|}{$\begin{array}{c}\text { Standardized } \\
\text { Coefficients }\end{array}$} & \multirow{2}{*}{ Sig. } \\
\cline { 2 - 4 } & \multicolumn{1}{|c|}{ B } & \multicolumn{1}{c|}{ Std. Error } & \multicolumn{1}{c|}{ Beta } & & \\
\hline (Constant) & 5.689 & 0.652 & & 6.712 & .000 \\
1 & .593 & .164 & .260 & 2.432 & .001 \\
Kec.Emosional & .564 & .278 & .472 & 3.712 & .000 \\
Motivasi & .549 & .290 & .311 & 3.830 & .001 \\
\hline
\end{tabular}

a. Dependent Variable: Kinerja Guru

\section{a. Pengujian pengaruh variabel Kecerdasan Emosional $\left(\mathbf{X}_{1}\right)$ terhadap Kinerja Guru (Y)}

Secara parsial uji statistik yang digunakan adalah uji t. hasil perhitungan SPSS berdasarkan tabel Coefficients, diperoleh nilai t hitung 2,432 dan $\mathrm{t}$ tabel 2,04, ini berarti bahwa nilai $\mathrm{t}$ hitung > nilai $t$ tabel $(2,432>2,04)$, dengan nilai signifikansi $0,001<0,05$ maka H01 ditolak dan Ha1 diterima. Hal ini berarti hipotesis diterima yaitu Kecerdasan Emosional berpengaruh positif dan signifikan terhadap Kinerja Guru di SMA Persiapan Stabat Kabupaten Langkat.

\section{b. Pengujian pengaruh variabel Motivasi (X2) terhadap Kinerja Guru (Y)}

Secara parsial uji statistik yang digunakan adalah uji t. hasil perhitungan SPSS berdasarkan tabel Coefficients, diperoleh nilai t hitung sebesar 3,712 dan $\mathrm{t}$ tabel 2,04, ini berarti bahwa nilai $\mathrm{t}$ hitung $>$ nilai $t$ tabel $(3,712>2,04)$, dengan nilai signifikansi $0,000<0,05$ maka H01 ditolak dan 
Ha1 diterima. Hal ini berarti hipotesis diterima yaitu Motivasi berpengaruh positif dan signifikan terhadap Kinerja Guru di SMA Persiapan Stabat Kabupaten Langkat.

c. Pengujian pengaruh variabel Komitmen (X3) terhadap Kinerja Guru (Y)

Secara parsial uji statistik yang digunakan adalah uji t. hasil perhitungan SPSS berdasarkan tabel Coefficients, diperoleh nilai t hitung sebesar 3,830 dan t tabel 2,04, ini berarti bahwa nilai $t$ hitung > nilai t tabel $(3,830>2,04)$, dengan nilai signifikansi $0,001<0,05$ maka H01 ditolak dan
Ha1 diterima. Hal ini berarti hipotesis diterima yaitu Komitmen berpengaruh positif dan signifikan terhadap Kinerja Guru di SMA Persiapan Stabat Kabupaten Langkat.

\subsubsection{Uji Determinasi $\left(\mathbf{R}^{2}\right)$}

Uji determinasi ini untuk melihat seberapa besar Kecerdasan Emosioal, Motivasi dan Komitmen menjelaskan Kinerja. Untuk dapat mengetahui besarnya Determinasi Kecerdasan Emosional, Motivasi dan Komitmen menjelaskan Kinerja dapat dilihat pada tabel berikut ini:

Tabel 6. Koefisien Determinasi

Model Summary ${ }^{\mathrm{b}}$

\begin{tabular}{|l|r|r|r|r|r|}
\hline Model & \multicolumn{1}{|c|}{$\mathrm{R}$} & $\mathrm{R}$ Square & $\begin{array}{c}\text { Adjusted R } \\
\text { Square }\end{array}$ & $\begin{array}{c}\text { Std. Error of } \\
\text { the Estimate }\end{array}$ & $\begin{array}{c}\text { Durbin- } \\
\text { Watson }\end{array}$ \\
\hline 1 & $.746^{\mathrm{a}}$ & .556 & .534 & 6.3785 & 2.825 \\
\hline
\end{tabular}

a. Predictors: (Constant), X1, X2, X3

b. Dependent Variable: $Y$

Berdasarkan tabel diatas didapat nilai $\mathrm{R}$ Square sebesar 0.556 atau 55,60\%.. Maka dapat dijelaskan bahwa variabel Kecerdasan Emosional (X1), Motivasi (X2) dan Komitmen (X3) berpengaruh sebesar 55,60\% terhadap Variabel Kinerja Guru di SMA Persiapan Stabat Kabupaten Langkat, sisanya sebesar 44,40 \% lagi dipengaruhi oleh Variabel lain yang tidak diikutkan dalam penelitian.

\section{Kesimpulan}

Dari pembahasan hasil penelitian diatas, maka dapat diambil beberapa kesimpulan dan saran Berdasarkan pada penjelasan yang telah dilakukan, maka penelitian ini memberikan suatu kesimpulan sebagai berikut:

a. Variabel Kecerdasan Emosional berpengaruh positif dan signifikan terhadap Kinerja Guru di SMA Persiapan Stabat Kabupaten Langkat, dengan nilai $t$ hitung $>$ nilai $t$ tabel $\quad(2,432>$ 2,04 ) dan pengaruhnya sebesar 0,593 atau $59,30 \%$.

b. Variabel Motivasi berpengaruh positif dan signifikan terhadap Kinerja Guru di SMA Persiapan Stabat Kabupaten Langkat, dengan nilai $\mathrm{t}$ hitung > nilai $\mathrm{t}$ tabel $(3,712>2,04)$ dan pengaruhnya sebesar 0,564 atau 56,40 $\%$.

c. Variabel Komitmen berpengaruh positif dan signifikan terhadap Kinerja Guru di SMA Persiapan Stabat Kabupaten Langkat, dengan nilai t hitung > nilai t tabel $\quad(3,830>2,04)$ dan pengaruhnya sebesar 0,549 atau 54,90\%.

d. Variabel Kecerdasan Emosional, Motivasi dan Komitmen berpengaruh positif dan signifikan terhadap Kinerja Guru di SMA Persiapan Kabupaten Langkat, dengan nilai $\mathrm{F}$ hitung > nilai $F$ tabel $(12,201>2,87)$ dan pengaruhnya sebesar 0,556 atau $55,60 \%$.

\section{DAFTAR PUSTAKA}

Arikunto, S. 2002. Prosedur Penelitian: Suatu Pendekatan Praktek, Penerbit Rineka Cipta, Jakarta

Arianto Sam. 2008. Pengertian Prestasi Belajar. [online]. http://sobatbaru.blogspot.com/2008/06.

Bandura, A. 1995. Self Efficacy in Changing Societies. USA: Cambridge University Press.

Bafadal, Ibrahim. 2004. Manajemen Perlengkapan Sekolah Teori dan Aplikasinya. Jakarta: Bumi Aksara.

Djamarah, Syaiful Bahri dan Aswan Zain, 2006 Strategi Belajar mengajar, Jakarta:PT Asdi Mahasatya.

Friedman, H. S.\& Schustack, M. W. 2006. Kepribadian Teori Klasik dan RisetModern Jilid 1. Jakarta: Erlangga.

Gie, The, Liang 2002. Cara Belajar Yang Efisien. Yogyakarta : Liberty.

Gitosudarmo, Indriyo,. Mulyono, Agus. 2001. Prinsip Dasar Manajemen Edisi Ketiga. Yogyakarta: BPFE.

Ghozali, Imam. 2005. Aplikasi Analisis Multivariatedengan program SPSS, Badan Penerbit Universitas Diponegoro, Semarang.

Gomes, Faus Cardoso. 2003. Manajemen Sumber Daya Manusia. Yogyakarta: PT Andi Offset. 
Hair . 2010. Multivariate Data Analysis, Seventh Edition. Pearson Prentice Hall.

Handoko, T.H, 2000, Manajemen, Badan Penerbit Fakultas Ekonomi UGM, Yogyakarta.

Hasibuan, M.S.P. 2004. Manajemen Sumberdaya Manusia, Penerbit: Gunung Agung, Jakarta.

Kalisa Evayana ,dkk.2012. Pembelajaran Menulis Teks Negosiasi Siswa Kelas X SMA N 1 Peingsewu. Pringsewu. Lampung. Volume 9, Nomor 2.

Kreitner, Robert,Kinicki, Angelo, 2003, Penterjemah Erly Suandy, Perilaku Organisasi, Edisi pertama Salemba Empat, Jakarta.

Mangkunegara, 2001. Manajemen Sumberdaya Manusia Strategik. Rosda Karya, Bandung.

Mudhoffir. 1992. Prinsip-Prinsip Pengelolaan Pusat Sumber Belajar. Bandung : PT Remaja Rosdakarya.

Mathis, Robert L dan Jhon H. Jackson, 2001. Manajemen Sumber Daya Manusia, Buku I, Pener ernah Jimmy Sadeli dan Bayu. Prawira Hie, Salemba Empat, Jakarta.

Mangkuprawira, Sjafri ， 2004, Manajemen sumber Daya Manusia Stratejik, Cetakan ke2, Ghalia, Indonesia

Nimran Umar, 2006. Perilaku Organisasi, Cetakan Ketiga, CV. Citra Media, Surabaya.

Nawawi, Hadari. 2001. Manajemen Sumber Daya Manusia untuk Bisnis yang Kompetitif.Cetakan Keempat.Penerbit Gadjah Mada University Press, Yogyakarta.

Newstorm dan Davis, 2002,Perilaku Dalam Organisasi.Edisi Tujuh. Jakarta: Erlangga.

Nurdin. 2009.'Implementasi Pendekatan CTL (Contextual Teaching and Learning) Dalam Meningkatkan Hasil Belajar".Jurnal Administrasi Pendidikan

Ormrod, J.E. 2008. Psikologi Pendidikan : Membantu Siswa Tumbuh Dan Berkembang. Jakarta : Erlangga.

Rivai,Veitzal 2004. Manajemen Sumberdaya Manusia Perusahaan, PT Raja Grafindo Persada, Jakarta.

Robbins, Stephen P., 2001, Perilaku Organisasi: Jilid 2, Penerbit Prenhallindo, Jakarta.

Santrock, J. W. 2007. Adolesence: Perkembangan Remaja. Jakarta:Erlangga. 2005. Life Span Development, Perkembangan Masa Hidup.Edisi kelima jilid 2 (terjemahan Chusaeri dan damanik). Jakarta: Erlangga.

Reksohadiprojo 2002. Dasar-Dasar Manajemen. Yogyakarta:BPFE
Rohani, Ahmad 2004. Pengelolaan Pengajaran. Jakarta. PT Rineka Cipta

Schneider, A.A. 2005. Personal Adjustment and Mental Health. New York: Holtt. Renehart and Winston Inc.

Sugiyono. 2012. Memahami Penelitian Kualitatif'. Bandung : ALFABETA.

Supardi dan Anwar. 2002. Motivasi Kerja.Puri Arsita Anam. Yogyakarta.

Siagian, Sondang. 2002. Manajemen Sumber daya Manusia, PT. Bumi Aksara, Jakarta.

Sam, Arianto 2008. Pengertian Prestasi Belajar.[online]. Tersedia: http: // sobatbaru.blogspot.com/2008/06/pengertianprestasi-belajar.

Uzer, Usman,. 2005. Menjadi Guru Profesional. Bandung: Remaja Rosdakarya.

Widjaya, Cece. 2000. Kemampuan Dasar Guru dalam Proses Belajar Mengajar.

Bandung: Rosda Karya.

Wlodkowski, R.J. dan Jaynes, J.H. 2000. Motivasi Belajar. Jakarta : Cerdas Pustaka.

Wahid, Murni, 2000. Evaluasi Pembelajaran, Kompetensi dan Praktik. Yogjakarta: Nuha Litera

Winkel.(2005). Psikologi Pengajaran. Yogyakarta: Media Abad.

Zamroni. 2003.Paradigma Pendidikan Masa Depan. Yogyakarta:Bigraf Publishing 